\title{
浅析互联网技术在工程管理中的应用
}

\author{
肖昊 梅燕飞 \\ 云南经济管理学院 \\ DOI:10.18686/bd.v1i10.1039
}

[摘 要]工程管理利用互联网技术的先进性和快捷性可以建立一个信息交换平台,通过该平台可以实现管理工作的信息 化和高效化, 从而更好地为项目工程的决策、项目施工的调整、项目风险的规避以及项目效益的管理提供信息情报方面的 支持。本文阐述了互联网技术在工程管理中应用的优势,对互联网技术在工程管理中的应用及其措施进行了探讨分析。

[关键词] 互联网技术;工程管理;应用;优势;措施

\section{1 互联网技术在工程管理中应用的优势}

利用网络技术和计算机处理技术可以对工程信息进行 对应的搜集、整理、计算、加工以及处理。在网络技术支持下 的工程信息管理方式能够使得项目管理人员在日常工作中 不论身处何地, 都可以快速的与施工作业人员进行有效的 沟通, 施工作业人员可以实时的进行施工质量报告、反映工 程进程、提出施工建议等, 并且处于施工现场的工作人员还 可以利用互联网将工程施工季度、质量检测报告等信息实 时上传至企业总部，从而迅速的缩短信息传递和沟通过程 中的耗时,确保信息传递的准确性和时效性,提高整个工程 项目的管理效率和管理精度。

\section{2 互联网技术在工程管理中的应用分析}

工程管理在管理系统的构建过程中通过利用互联网技 术的工程信息系统能够显著提高管理的效率和管理质量。 (1)在进度管理中的应用分析。当前工程施工进度管理工作 中主要使用的是由专业人员开发的在建筑行业内部使用的 局域网络, 这种局域网络具有显的行业特征, 就目前情况 看,这方法也较为适合我国的基本国情,尤其适合对外工程 承包的实际应用需求。基于互联网技术的工程管理网络体 系的构建能够随着互联网技术的整体发展而发展, 并逐步 被更多的部门所应用, 因而可以在提高工程施工进度管理 实时性的同时保证工程质量可靠性。(2)在费用管理中的应 用分析。工程费用是工程造价管理的重要对象, 利用互联网 技术可以将管理工作具体到每一个人，使得整个工程造价 得到全面控制。在实际的工程管理过程中, 工程造价管理工 作受到建设单位、施工企业以及其他管理部门的制约, 为了 提高费用管理水平，一个重要方法就是对工程预算的管理 方式进行改良,在此基础上,逐步形成一整套有效、精确的 报价方法。所以,在工程费用管理中应用基于互联网技术的 造价管理系统成为了当前造价管理的人员的共识。(3)在索 赔管理中的应用分析。索赔是工程建设合同双方在合同履 行过程中不可忽视的重要方面, 企业为了维护自身的正当 权益, 必须加强自身的索赔观念, 并做好索赔管理工作, 以 免赔付其中不应该由自身承担的部分。利用基于互联网技 术的工程管理方法可以将工程建设过程中产生的所有信息
进行分类、计算、存储,为索赔管理工作提供翔实的依据。

\section{3 互联网技术在工程管理中应用的措施}

3.1 科学构建层次化的工程管理平台

工程管理工作涉及范围广、内容繁杂, 向外可以延伸到 建筑图纸设计、工程建立、地方行政管理人员等多个方面: 向内则可以延伸到工程合同管理、工程监督、建设资金管 理、工程造价管理、材料采购等多个环节, 因此, 在使用互联 网技术构建工程管理平台的过程中应该不只是停留在单一 的方面,而应该构建层次化的管理信息平台,使得工程管理 涉及的各类信息都能够获得信息化的处理。

3.2 健全完善工程管理系统

由于工程管理涉及的内容繁杂、环节多, 尤其是在项目 立项、招投标过程中会涉及其他方面的不同标准,在这个过 程中需要引人大量的数据, 使得工程管理系统不但数据库 庞大,而且计算量也极大。因此, 为了保证工程项目管理过 程中的成本管理、定额统计、质量管理、人员安排、材料采 购、施工工艺等内容能够及时、快速的满足施工管理的需 要, 应该使用科学便捷的技术手段将整个建筑项目施工前 后的各项内容整合起来,从而形成一个全方位、全过程的工 程管理信息平台, 该平台还要具有响应快速、数据完整的功 能, 这一功能只有借助于互联网技术的支持才能得以实现。

\section{3 不断创新工程管理流程}

工程管理工作中涉及诸多的数据信息，而这些数据信 息会在各个环节中流通和使用。如果构建一个基于互联网 技术的工程管理系统，就能够使用工程信息数据库根据管 理规范进行精确的信息搜集、组织、存储、处理与传播, 并且 应用数据库管理技术能够及时、准确地获得经过精确处理 之后的各类数据, 并且还可以生成直观、清晰的图表等内 容,在保证结果准确的同时实现了信息资源的可重复利用。

\section{4 结束语}

随着计算机通信技术的发展和广泛普及，基于网络技 术的工程管理技术开始在工程管理中得到逐步应用, 建筑 企业通过在企业自身内部建立完整的局域网络, 并使用自 主开发或者商业信息化管理系统，初步实现了工程管理的 信息化。在互联网技术的支持下,建筑企业可以在日常管理 


\title{
影响建筑工程施工质量的因素与策略研究
}

\author{
黄俊翔
}

贵港国家生态工业( 制糖) 示范园区管理委员会

DOI:10.18686/bd.v1i10.1002

[摘 要] 建筑工程施工质量直接关系到国家的发展建设以及人们的生命财产安全。本文围绕建筑工程施工进行讨论, 介 绍影响建筑工程施工质量的因素, 探讨相应的解决对策, 希望可以进一步的加强建筑工程的施工质量, 推动建筑行业的可 持续发展。

[关键词] 建筑工程;施工质量;影响因素;策略

随着经济建设的发展, 建筑行业得到了快速的发展。对 于建筑工程来说, 质量就是它的灵魂所在, 也是建筑行业发 展的必要条件, 建筑工程的施工质量不但会对企业经济效 益造成一定的影响, 更关系到企业的长远发展, 所以建筑企 业必须要对建筑工程的施工质量加强控制, 通过完善相关 制度,制定具有科学性、合理性的管理模式, 使各项职责得 到明确的划分, 从而提高建筑工程的施工管理质量, 使建筑 工程的施工得到有效的控制, 从而提高建筑工程的施工质 量,使企业发展的稳定性得到保证。

\section{1 影响建筑工程施工质量的因素}

1.1 人为因素对建筑工程施工质量的影响

工程的管理者和施工者是整个建筑工程施工的主要参 与人员, 对于建筑工程而言, 他们是施工的主体, 他们自身 的综合素质能力会对建筑工程的施工质量造成直接的影 响, 如果施工者缺乏专业的知识技能, 在施工过程中频繁出 错或违规操作, 而管理者管理能力有限在施工过程中疏于 管理,都会对工程施工的质量造成严重的影响,所以,建筑 单位在对工程设计、施工及管理人员进行选择时, 必须将质 量把控工作做好, 将专业技能和综合素质作为最基本的任 用条件, 除此之外, 还要定期对相关人员展开专业的培训, 使其综合素质能力得到有效培养, 从而保证建筑工程的施 工质量。

\section{2 材料因素对建筑工程施工质量的影响}

在建筑工程当中,建筑材料可以说是它的物质保障, 材 料的质量与建筑工程的施工质量具有非常密切的关联, 在 进行建筑工程施工时, 施工单位为了使经济效益最大化, 往 往会以价格作为材料采购的首选条件, 对材料的质量问题 较为忽视, 这样采购的工程材料, 难以保证质量, 自然也就 无法保证建筑工程的施工质量, 很可能会在建筑工程当中

中应用专业管理软件进行工程管理，这对企业在提高工程 项目管理效率、降低施工成本、提高施工质量等方面具有重 要意义。

\section{参考文献:}

[1]千素云.基于互联网技术的建筑工程管理 [ J]. 科技
埋下安全隐患,从而影响工程后期的正常使用。

1.3 施工方法因素影响建筑工程施工质量

施工组织设计方法、施工技术以及施工质量检测方法 是组成建筑工程施工方法的主要内容, 在进行具体施工时, 部分技术人员或管理人员对施工方法进行盲目的更改, 往 往会导致施工规范或施工制度流于形式。例如，一些技术人 员在进行施工时, 没有对工程施工的具体情况进行考虑, 不 按规定要求的施工方法进行施工, 仅依靠自己的施工经验 进行操作, 施工方法应用缺乏科学性及合理性, 从而对工程 的施工质量造成影响。

\section{4 施工制度因素影响建筑工程施工质量}

各行业各当中都具有专项的管理制度, 在建筑行业当 中也是如此。在对建筑工程进行施工时, 会严格按照相关的 制度规范进行施工, 制度的有效约束, 可以明确建筑工程施 工中的各项职责, 从而保证每个人都能在施工过程中坚守 岗位职责, 使整个施工过程得到有效的保证, 但在实际的建 筑工程施工中, 缺乏完善的施工制度或施工制度无法贯彻 落实的现象却普遍存在, 而这些问题都会对工程的施工质 量造成严重的影响。

\section{2 强化建筑工程施工质量的具体策略}

2.1 在建筑工程当中严格执行市场准人制度

相关部门要做好建筑工程的把关工作, 对建筑工程施 工中各参与方的资质进行严格的审查, 明确规范市场准人 制度, 从而保证施工队伍的专业素质能力, 使工程的施工质 量得到保证, 如果发现设计单位或施工单位的资质不达标 准, 应予以淘汰, 不得发布许可, 并在建筑行业当中推行施工 质量认证制度, 而国家相关质量监管部门应针对建筑工程 中的重要环节进行检验, 从设计、施工以及材料选择等方面 人手, 进行专项检查, 待检验合格以后方可发布质量证书,

经济市场,2016(02):151-152.

[2]杽笏.电子工程信息系统技术在公路工程管理中的 应用探讨[J].建材与装饰,2016(40):223-224.

[3]周静. 互联网 + 对工程造价行业的影响 [J]. 建筑建 材装饰,2016(06):88. 